\title{
Chapter 11 \\ Out with the Old, In with the New? \\ From Conceptual Reconstruction \\ in Philosophical Anthropology \\ to a Realistic Theory of Change
}

\author{
Wesley J. Wildman
}

\begin{abstract}
Philosophers have solid analyses of defective understandings of the human condition and regularly propose inspirational alternatives that would seem to have the promise of changing the fortunes and fate of our species. But philosophers sometimes over-generalize in their criticisms, attributing to a vast cultural complex a specific anthropological understanding when in fact any large culture plays host to a large variety of mutually inconsistent anthropological visions. Moreover, philosophers rarely demonstrate that a culture-level change in anthropological understandings would have the effects they claim and they virtually never spell out a theory of change by which such a culture-level transformation could ever be realized. This paper begins in philosophical anthropology, spelling out two specific problematic aspects of contemporary western human self-understanding: individualism and cognitive error; two corresponding correctives: relationality and self-awareness; and two spiritual translations of these corrective measures: love as agape and karuna and wisdom as knowledge and humility. The argument then transitions to practical questions about what differences the envisaged transformation in ideas about human nature might be expected to make on socioeconomic conditions and how such changes might be implemented to realize the envisaged changes. The conclusion is that the anthropological insights of philosophers would be best served by a partnership with education and policy experts that would add realism about the conditions for social change to the generative creativity of philosophical analysis.
\end{abstract}

\footnotetext{
W. J. Wildman $(\bowtie)$

Boston University, Boston, MA, USA

e-mail:wwildman@bu.edu
} 


\subsection{Pinning Down a Slippery Problem}

Philosophers aren't very important as agents of social change. Maybe they never were. After all, Confucius was reportedly frustrated at not being able to realize his vision for ancient Chinese society and Plato's Republic never made it off the page. Even Karl Marx's socioeconomic vision was realized very differently than he had intended, in every instance. If there were past eras when philosophy had a large voice in social organization, philosophers certainly seem to have little impact on socioeconomic realities these days. The great idea brokers of our time are public intellectuals who blend a dash of philosophical insight with impressive depth and breadth of knowledge and a formidable talent for communication. We call them thought leaders and opinion makers because they influence the way regular people think.

Yet, philosophers have always had great ideas, and that's as true today as it has ever been. The danger of people blessed with splendid ideas is that they can overestimate the social influence of great ideas in the past. They can also harbor unduly optimistic estimations of the social potential of their own ideas today. Just as moral reasoning for most people is a process parallel to and somewhat independent of nearly automatic moral appraisals and actions, so philosophical reflection on what society most needs appears to be a process parallel to and somewhat independent of the reflexive operation of a society. Philosophy happens but with uncertain causal influence, at best.

For example, did John Stuart Mill's understanding of human beings as what his critics would later call Homo economicus - "a being who desires to possess wealth, and who is capable of judging the comparative efficacy of means for obtaining that end" (Mill 1836) - have any determinate effect on the way regular people behaved in society? I think few people ever bought into it back in the nineteenth century nor at any time since. An informal survey of my acquaintances reveals that most people think of it as ridiculously reductive and contrary to the way they behave - and that's true even of those among them who are personally oriented to wealth accumulation. Even Mill treated the definition as an abstraction intended to indicate the scope of the emerging science of economics, as the preceding part of the sentence demonstrates: "Political economy ... does not treat the whole of man's nature as modified by the social state, nor of the whole conduct of man in society. It is concerned with him solely as a being... [etc.]." He's giving a definition of political economy, not of human beings; his view of human beings as such was far richer. To my way of thinking, Mill was postulating the abstracted definition of human being as a premise for further analysis and reflection specifically within the science of economics. Not many people are perfectly rational actors, solely concerned with accumulating wealth, yet that assumption can found a science of economics that generates a flurry of new and powerful insights. This hypothetical, almost experimental, limitation on the scope of economics became a pillar of economics textbooks for decades after Adam Smith and Mill but even that didn't cause most regular human beings suddenly to conform to that definition of their economic nature. There are so many 
more pressing issues impacting economic behavior than what a bunch of nineteenthand early twentieth-century economists and philosophers said about the best abstractions for leveraging insight-generating analyses of economic systems.

I'm not arguing that all causes for socioeconomic behavior are proximate and none distal. On the contrary, a large body of well replicated experimental work in social psychology has demonstrated that people unconsciously react to awareness of finitude and death with aspirational life projects that bolster self-esteem, with investments in close relationships for comfort and material support, and with vigorous defense of worldviews (for an overview, see Solomon et al. 2015). These are distal effects and they are not detectable until some time passes after experimental subjects are primed with thoughts about death. But they are powerful contributing factors to a host of socioeconomic realities, from building up a business to maintaining safe family neighborhoods, to xenophobic reactions toward refugees taking jobs that locals might have had. Those unconscious behavioral strategies for managing death anxiety no doubt partially underwrite the kind of single-minded wealth acquisition and rational maximization of means to that end that Mill had in mind. I feel confident that such real-life motivations, conscious and unconscious, dwarf in magnitude whatever influence Mill's understanding of the scope of the science of economics may have had on western socioeconomic practices.

Nevertheless, I think there's a broad consensus that contemporary western societies confront daunting threats, some global in scope, that seem to be traceable in part to a deeply flawed operative understanding of human nature implicit within our societies and economies and politics. I doubt that these flaws can be traced back to the conceptual model of human beings as rationally choosing, wealth-maximizing economic actors, because that was never much more than a premise for limiting the scope of the discipline of economics in its early years and has been routinely contested ever since, inside and outside of economics. Moreover, there are countless examples of economic cultures that operate very differently, on principles of reciprocity, or honor, or morally inflected indebtedness that underwrite very different visions of the economic aspects of human being. It follows that the problem of flawed anthropological concepts does not lie in the science of economics, however flawed that may or may not be as a science, and it won't be the same problem in every culture, because cultures vary rather colorfully in their visions of human nature, even though every culture has some operative means of economic exchange. Focusing on North Atlantic cultures and the associated democratic, capitalist socioeconomic systems adds some welcome and needed specificity.

In western settings, the deep flaws in the operative understandings of human nature implicit within our societies and economies and politics relate primarily to individualism and cognitive error, in my view.

By individualism, I refer to a structure of rationalization, a pattern of thinking in forms of socioeconomic coordination that easily leaves vulnerable people behind in ways that might seem cruel to an outsider. Within the cultures where this occurs, individualism effortlessly rationalizes such behavior with an emphatic assertion of rights, rewards, and responsibilities articulated primarily at the individual level. That is: I as an individual have the right to as much wealth as I can or want to 
accumulate; I as an individual deserve whatever wealth and privilege I can amass; I as an individual am responsible primarily for myself and only secondarily, in circles of attenuating intensity, for my family, my neighborhood, my society, my nation, and my planetary habitat. Most western nations have taxation systems and government-funded safety nets designed to mitigate the problem of the marginalization of the vulnerable to some degree. In some nations - the United States in particular - indignant, individualistic moral rationalizations for neglecting and oppressing poor and vulnerable human beings are pervasive. Such individualistic rationalizations express a particular understanding of fairness: not fairness as "From each according to his ability, to each according to his needs," which was a slogan popularized by Marx, but fairness as "people who are the most talented and the most hard-working should be paid the most," which is constantly on guard for freeloaders who would benefit from social goods without contributing. Individualism is a crucial rationalizing adjunct to this understanding of fairness.

By cognitive error, I refer to our cognitive limitations in the face of the enormously complex socioeconomic systems we have built. We have terrible difficulty understanding the causal processes driving the emergent features of these complex systems and cling to simple but false explanations to ease cognitive load when analysis and prediction would be better served with a cognitively more demanding approach to complexity. The result is baffling and frustrating. Good-hearted people can end up perpetrating devastating socioeconomic violence on others and really have no idea how to stop, even though they would never willingly harm people in that way if they had greater control over their situation. Even generally selfish people wouldn't normally harm themselves in the manner of human-abetted climate change, but the climate system is formidably complex, the links to socioeconomic systems incredibly tangled, the cognitive challenge seemingly insurmountable, and solutions profoundly disruptive and painful. It is easier to deny the problem or to satisfy ourselves with simple actions such as recycling, telling ourselves that we are doing our part, even though such actions are largely irrelevant to solving the underlying problem.

If the line of my reasoning to this point is sound, then philosophers face an interesting puzzle. We certainly should not stand idly by and fail to engage with threats such as climate change or economic injustice, particularly since philosophers can offer potent alternatives to the unhealthy prevailing concepts of human nature that directly address the problems of individualism and cognitive error. But the threats are urgent enough that there is little point in thinking philosophically about reconstructing concepts of human nature in these two dimensions if we don't also have a practical plan to change the socioeconomic practices that most concern us. If we ignore the need for change, philosophers pondering human nature may end up being the philosophical equivalent of Wallace Hartley's band playing soothing music on the Titanic even as the great boat filled with water and everyone scrambled to escape. Thus, I believe we need both conceptual reconstruction and a theory of change.

Typically, philosophers are very good at conceptual reconstruction and very bad at generating feasible theories of change. Fortunately, educators and policy 
professionals arguably need help with conceptual reconstruction and are often excellent at generating practical methods for social change. A strategic partnership seems called for, as a result. Admittedly, philosophers may need educators and policy professionals more than those two groups need philosophers. After all, without professional help, the best philosophical ideas remain inert outside of specialized communities of philosophical debate, whereas educators and policy professionals may feel that philosophical niceties run a distant second to creating literate human beings and leveraging positive social change. Nevertheless, I find a partnership between philosophers and educators and policy professionals to be an intriguing possibility and well worth pursuing.

The June 2019 Homo Amans symposium in The Netherlands represented an opportunity to move from conceptual reconstruction of "human nature" to a feasible theory of socioeconomic change. Perhaps the downstream consequences of that symposium will include philosophers working with educators and policy professionals on shared goals for worldview restructuring, synchronized with socioeconomic transformation. Arguably, in the era of the Anthropocene, which is already manifesting perilous socioeconomic side effects of climate change, nothing could be more important.

\subsection{Conceptual Reconstruction}

Let us begin in the domain of philosophical anthropology, asking about ways of thinking that we imagine might improve human life if they were incorporated into the living imaginaries of our time. For now, we can set aside the realism-drenched question of how any concrete changes might actually be achieved.

\subsubsection{Framing Considerations}

There are numerous definitions of the human being, each attempting to capture the essence of our species. In my own work in philosophical and theological anthropology, I have declined the temptation to offer an essentializing definition, instead focusing on species-wide characteristics and patterns of individual and cultural variation (Wildman 2009). The species-wide characteristics are a rich array of evolutionarily stabilized features ranging from cognitive capacities, including crosscultural tendencies to cognitive error, all the way to recurring cultural features, such as means of exchange and regulation of sexual activity. Individual variations stretch from gender and sex to personality and intelligence. Cultural variations extend from language to religion. Species-wide characteristics might be thought of as essential, in the sense of almost universally present, and could be the basis for an essentializing definition if you wanted one, but the individual and cultural variations are just 
as important for generating a reliable understanding of the nature of our species, and they tend to be masked when the focus is on assertions of a human essence.

For this reason, I prefer a multi-vocal approach to articulating human distinctiveness, one that keeps the biological and cultural dimensions of human life tied closely to one another, and human beings in their complex bodily reality firmly rooted in the rest of physical nature. Doing this well demands the participation of numerous university disciplines - in fact all disciplines that have anything to say about human beings. It may not be possible always to harmonize everything that academic disciplines say about human beings but, all in all, I find there is an impressive convergence of angles of analysis in what I have called the "modern secular interpretation of humanity." This relative (not perfect!) consensus begins to break down as we move to richer levels of interpretation, where we grapple with human beings as meaning-making animals whose adventures in meaning are borne within cultural trajectories of world exploration. This is where we see profound and probably irresolvable disagreements about the origins and destiny and meaning of human beings, expressed in potent stories that enliven various cultural forms even as those stories slowly mutate over time to accommodate new socioeconomic and cultural realities. And yet, these days, the modern secular interpretation of humanity exercises a profound regulative effect on these stories, causing some to die if they pass too far into the territory of implausibility, and others to adapt so as to maintain plausibility for those who find the stories to be life-giving.

With those framing assumptions in place, I'll take up the two themes of individualism and cognitive error, in light of the modern secular interpretation of humanity. I'm interested in the implications of these two concepts for our self-understanding as socioeconomic beings. I'm equally interested in what would happen if new ways of thinking supplanted these aspects of our self-interpretation as human beings and were incorporated into living imaginaries, from where they could impact socioeconomic behavior. The attendant changes are critical for the human future. I'll defer discussion of that until the next section. In this section, attention is on philosophical anthropology.

\subsubsection{Individualism, Relationality, and Love as Agape and Karuna}

Individualism in the sense I give it above is somewhat novel in the history of our species. Other hyper-social species, such as bees, consist of individual bees, in a sense ultimately underwritten by physically distinct bodies that are born, move, and die - this despite their profound dependence on one another in everything from the microbial to the social dimensions of bee life. Despite similar connections and dependencies among human beings, the complexity of human minds, the hiddenness of our thoughts from others, and the way we hold individual human beings responsible for their actions, jointly invite an intensification of individualism. Most human cultures balance that individualizing tendency with religiously and 
politically enforced moral norms about obligations toward others that bind individual identity to satisfying those obligations. What's interesting and exceptional about western cultures after the solidification of capitalism and democracy is the partial severing of individual identity from social obligations, permitting individualism to attain degrees of intensity rarely or never seen in the long history of our species. For instance, young people in western cultures are now expected to become independent of their parents, financially, emotionally, and in terms of end-of-life care. Western individualism is not so extreme that we dispense with social obligations; after all, laws are enforced, schooling is a social-hive activity, and the vast majority of parents teach their children to be other-regarding. But individualism is still unusually powerful in the west, not least because of its function in articulating and justifying a particular understanding of fairness, as noted above.

Running counter to western individualism, insights from the modern secular interpretation of humanity assert a profound relationality with the power to contest and correct the socioeconomically inspired hyper-individualism of western cultures. Numerous disciplines attest to the presence of intensive relationality at the root of life in general, and within human life in particular, but they do so in very different ways. Philosophical anthropology is a useful venue in which to attempt to assemble an interpretation of relationality that can benefit from and respond creatively to those varied disciplinary perspectives. These insights have the potential to transform human self-understanding, both in terms of the way we conceive our relationships with one another and in terms of the way we picture our relationship with the wider world of nature. Here are a few of those worldview-transforming insights, from the domain of the very small and very old to the domain of the very human and very recent.

- From physical cosmology and elementary particle physics, we learn that every aspect of material reality comes from the same source. Very early in the history of our universe, even the forces we now think of as separate - the gravitational force by which mass-energy warps space-time, electromagnetism that underwrites atomic structure and chemistry, the weak force associated with radioactive decay, the strong force that binds atomic nuclei - were indistinguishable. We are all related by virtue of coming from the same matter-energy.

- Though the early universe could only create light atoms (isotopes of hydrogen, helium, lithium), stars formed from those elements were able to generate a range of heavier but still relatively light elements, explosions of those stars produced enough energy to forge still heavier elements, and a second generation of stars with solar disks containing those heavier elements formed planetary systems and ultimately all of the lifeforms teeming over our planet. We are all related by virtue of coming from the same star-born atoms.

- The geological formation of planet earth is intimately related to the emergence of microorganisms, which both adapted to the planetary environment and transformed ecological conditions. Just as geology and microbiology are intimately bound, so that union is the condition for the possibility of more complex organisms to emerge. We are all related by virtue of the intimacy of organic and inorganic matter. 
- Biochemistry has revealed the mechanisms of intergenerational genetic transmission and protein expression, through which it has become clear that all earth organisms share the same deep biochemistry even when cellular chemistry changes among large classes of organisms. We are all related through participating in the same biochemical nexus of DNA and amino acids.

- Evolutionary biology has taught us about the intricate process by which complex organisms emerged from simpler lifeforms, uncovering a range of mechanisms of genetic change, including natural selection, which crafts adaptive bodies from environmental constraints, including social realities that underwrite stunning exhibitions of gene-culture co-evolution. We are all related by virtue of the evolutionary process.

- The energy processing factories within cells exist because of a symbiotic relationship with primitive bacteria, which were absorbed into cells and brought their ATP engineering capacities in with them. We are all related by virtue of sharing evolutionarily stabilized metabolic processes.

- The study of organism microbiomes shows that the life of any given plant or animal critically depends on a network of living organisms. No organism exists without intricate relationships with other organisms, including for food, and human beings die without the microorganisms that live in and on them. We are all related by virtue of being dependent on other life forms for our very existence.

- Attachment theory within psychology has revealed the potency of relationships between parents and their offspring, particularly within mammals and especially in primate species. Those formative attachments are critical for physical wellbeing and mental health. We are all related by virtue of our strong emotional links with other people.

- Life in social species is all about adapting to and thriving in novel environments through cooperation and problem solving. Group selection effects within evolution incentivize groups to minimize free-riders and embrace ritual strategies that encode group norms and bind us to one another for the sake of survival and protection. We are all related by virtue of our commitment to group-defining moral norms.

- Human beings are intelligent enough to tell and remember stories and to orient one another to life challenges by means of those stories. Such stories convey history and knowledge, hopes and dreams, cultural practices and social norms. We are all related by virtue of our investment in and reliance on culturally constructed imaginaries.

- Crossing back into physics, quantum entanglement has demonstrated that the commonsense view of local realism - that particles have definite properties and causes operate locally (no faster than the speed of light) - contradicts experiment. All viable interpretations of the quantum formalism, whether deterministic or indeterministic, are non-local, which entails a subtle and strange form of connectivity beneath the surface appearances of the ordinary world. We are all related by virtue of entanglement.

- Cognitive science of human beings has demonstrated cross-cultural similarities in cognitive operations. The stable species-wide character of human cognition is 
the basis for a significant degree of intelligibility and translatability despite notable differences in language, culture, religion, morality, personality, and ideology. We are all related by virtue of our evolutionarily stabilized brains.

The modern secular interpretation of humanity has generated an impressive consensus. By itself, this suggests that the relationality inherent in human life is multidimensional, consistent, irreducible to a single perspective, and extremely profound. Western hyper-individualism seems a particularly extreme and ultimately unsustainable adventure in the social construction of human nature in light of this rich perspective on relationality. We might regard the conception of socioeconomic fairness that hyper-individualism rationalizes - people who are the most talented and the most hard-working should be paid the most, and freeloaders should be identified and penalized for betraying their individual responsibilities - as similarly extreme. Arguably, that extremity is a sign of western cultural greatness. But maybe it is also the great weakness of western forms of socioeconomic cultural organization. I think the historical record demonstrates that extreme ideas often function as both enablers of novelty and seeds of self-destruction.

Moving beyond the powerful consensus within the modern secular interpretation of humanity to the more controversial territory of metaphysics, this depiction of relationality leans heavily away from the Aristotelian vision of "things" as substances that bear properties and toward the relational vision of "things" coconstituting one another in webs of mutually dependent co-arising. This radically intimate vision of relationality at the ontological root of every part of reality, if correct, would powerfully reinforce the relationality affirmed within the modern secular interpretation of humanity (Scaringe and Wildman 2020). In any event, there seems to be no question that the modern secular interpretation of humanity demands some kind of relational ontology (Wildman 2010). Relational ontologies do not outrightly contradict western hyper-individualism, but they do make hyperindividualism fundamentally implausible as a way of conceiving human nature, and thus offer conceptual resistance to the socioeconomic enshrinement of hyperindividualism whenever and wherever it occurs.

Within the moral and spiritual domains, an apt expression for the kind of relationality portrayed within the modern secular interpretation of humanity and its metaphysical extensions is love. Now, love is a famously complex and multi-faceted concept, so a word of clarification is in order. To begin with, human beings have three distinguishable neurological love systems: sexual attraction (mediated especially by testosterone), infatuation (mediated especially by dopamine), and bonding (mediated especially by oxytocin) (see a summary of these systems in Wildman 2019). These are something like the atomic components of the molecular formations of love in the evolutionary realities of reproduction and parental investment in offspring. There are also higher-order, phenomenologically distinguishable types of love, from love of friends to love of animals and from love of music to love of sports. Longstanding traditional typologies of love often begin at this level, understandably silent on what we have discovered about the neurology of love in recent decades. 
The morally and spiritually most profound types of love are of two main types. One is resolute benevolence, an alignment of intention and action for the benefit of others. The other is universal compassion. The first kind of spiritual love, often called agape, is more a matter of virtuous will than emotion. It first presupposes and then actualizes a profound relationality between persons that befits underlying relationality, conceived differently in the varied spiritual worldviews of our planet - this is the very relationality disclosed in reality through the modern secular interpretation of humanity. The second kind of spiritual love, often called karuna, is the fruit of spiritual practices that express a profound awareness of relationality, an awareness that can be cultivated in meditative states. Importantly, while the two types of spiritual love overlap, they are distinguishable. Agape does not require karuna, though feelings of empathy and compassion can be powerful motivators toward realizing the unconquerable benevolence of agape. Similarly, karuna does not require agape, but ordinarily universal compassion should lead outwards to precisely the kind of benevolent actions that agape prizes.

I contend that cultivating these two types of love is the spiritually most relevant and profound response to the disclosure of relationality within the modern secular interpretation of humanity. The vision of the human person expressed in the union of karuna and agape goes well beyond anything envisaged within that consensus interpretation from the contemporary university disciplines but they are conceptually consistent and mutually resonant.

\subsubsection{Cognitive Error, Self-Awareness, and Wisdom as Knowledge and Humility}

Let's turn to cognitive error. The human brain is phylogenetically dependent on a long process of brain evolution in other species. Critical tasks for the brains of most species include keeping the body running (e.g. autonomic nervous system), making sense of situations quickly enough to take effective action (e.g. rapidly changing bodily function in response to life-threatening dangers), and managing procreation (e.g. finding mates and protecting offspring). In human cognition, an overlay of higher cortical functions launches cognition into unprecedented realms of complexity. Memory is more powerful, simulation of future situations is more extensive, and information processing to interpret a situation is more intricate. For many purposes - indeed, for most purposes within the small-scale cultures of the era of evolutionary adaptation - human cognitive capacities were well suited to the natural hazards and social demands that human beings had to navigate. In complex cultures, however, where cognitive demands are much higher, our memory, our interpretative abilities, and our decision systems are often stressed. That's when we make mistakes, mistakes that we often don't recognize and typically can't avoid or fix.

These all-too-human tendencies to cognitive error have been studied exhaustively during the last century of research in cognitive psychology and documented voluminously (see Fig. 11.1 for the Codex of Cognitive Bias, which I prefer to call 

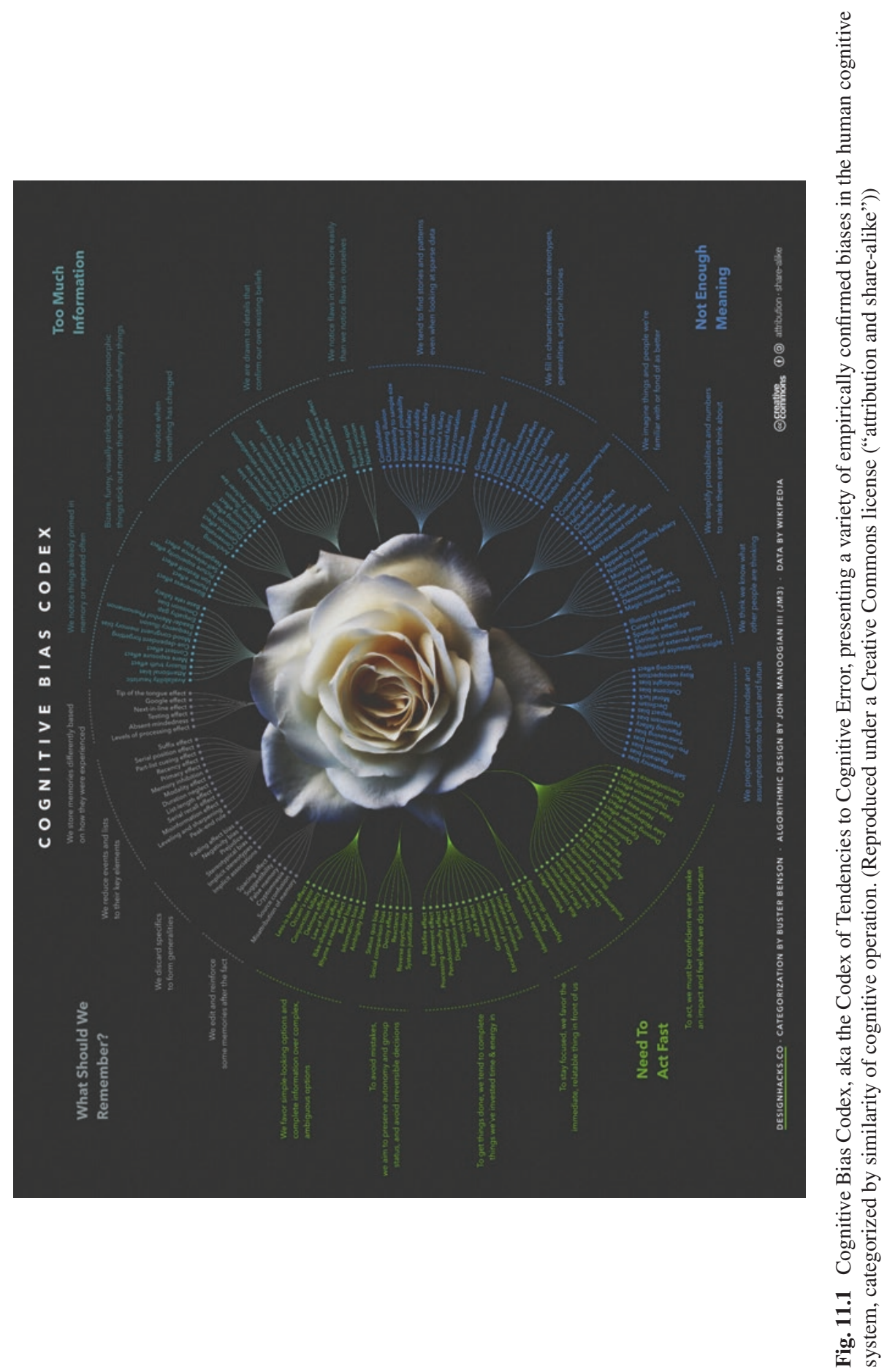
the Codex of Tendencies to Cognitive Error, emphasizing tendencies). Some of them are amusing: think of a magician taking advantage of the way human beings are known to interpret sensory information and doing something that appears impossible but in reality is merely deceptive. Other tendencies to cognitive error can be deadly: picture one group of people settling for cognitively easy negative generalizations about another group in lieu of detailed person-to-person information and then using those oversimplified generalizations to rationalize violence against the group they malign. Of course, there are lot of cognitive errors whose importance lies somewhere in between amusement and genocide (for application to human inquiry, see Wildman 2009).

In the case of attempting to interpret and transform the socioeconomic practices of western capitalistic democracies, tendencies to cognitive error play a critical role. Formally complex systems - e.g. large economies - display several mind-bending properties that play havoc with human cognition. Under some circumstances, they become highly unpredictable, which makes human beings extremely nervous because methods for satisfying their survival needs become fragile. The nexus of causes involved in a complex economic system is only partially understood, making interventions potentially perilous and always debatable, which also makes people nervous. Moreover, interventions can backfire producing unintended consequences, which can be very dangerous.

At a more personal level, since we lack control over the economic system as such, we cannot act meaningfully to improve the economic practices we don't like. We can complain and protest, of course, but it is extremely difficult constructively to contribute to a solution. That kind of despair is a rational reaction to being unwillingly caught up in perpetuating economic injustice and the resulting dissonant state of mind is difficult to tolerate so we tend to narrate our way out of the impasse with stories about other people's badness or about us doing our part. They might even be convincing stories at some level but they are fundamentally evasive and selfexculpatory, and they are oriented more to alleviating cognitive dissonance and moral anguish than to solving socioeconomic problems.

Naturally, the inevitable failure of experts to possess a sound grasp of a complex socioeconomic system leads to economic disasters and popular mistrust. That's a rational reaction, amounting to coming to terms with the complex nature of a modern economy. But experts are the only people able to gain much of a sense of the levers of a socioeconomic system, so an opportunity for cognitive error lurks nearby: we can all-too-easily generalize from skepticism about complete knowledge to wholesale mistrust in all experts, and thereafter agitate to replace so-called experts, who actually do possess the best knowledge available, with populist demagogues, who typically possess little relevant expert knowledge at all.

How do we mitigate the problems associated with being a species whose cognitive powers are optimized for cultural worlds far simpler than the one in which we actually live? The answer, surely, is a specific kind of self-awareness, one that recognizes the ever-present tendencies to cognitive error, inspiring us to regulate emotion and behave accordingly; one that recognizes the presence of a complex system and proceeds cautiously; one that is ready for the possibility of unintended, unwanted side effects of even the cleverest interventions. 
Consider a side effect of the advent of the internet, which revolutionized the global economy. Nobody boosting the internet imagined a massively amped-up market in every country and locality for the commercial sexual exploitation of children, linking buyers with sellers with an efficiency that was formerly impossible. Now that we do know about that unintended consequence, we are struggling to find effective ways of battling the problem. People self-aware in the way I'm now describing would have detected the opportunity for cognitive error lurking. They'd have been on the lookout for unintended side effects and they'd have been warning people in advance to expect them, even if they didn't know precisely what they would be.

Within the moral and spiritual domains, this kind of self-awareness might be called wisdom, and it has two important aspects: knowledge and humility. The knowledge aspect of this kind of wisdom involves knowing a lot, including and especially about tendencies to cognitive error. Acquiring knowledge requires training - a great deal of training - in cognitive science, logic, probability, ethics, and also in specific subject matters, such as political economy or climate science or whatever the specific problem in view may be. It also involves building character, which takes us to the humility aspect of this kind of wisdom. The humility aspect of wisdom is powerfully akin to what Christians might call consciousness of sin, what Buddhists might call right mindedness, and what secular humanists might call the ethics of systems thinking.

Wisdom recognizes the complexity of vast human social systems, and is resolutely skeptical about every kind of hubris, particularly those on a civilizational scale with the potential to impact billions of people and other animals besides us. Both the knowledge and humility dimensions of wisdom are virtues that can be cultivated - and absolutely must be cultivated if human beings are to successfully navigate the challenges we now confront.

\subsection{Theory of Change}

Love as agape and karuna, and wisdom as knowledge and humility are capable of confronting rampant individualism and unchecked tendencies to cognitive error within contemporary western socioeconomic systems. I think philosophers feel sure of this; after all, someone who has truly learned the lessons of love and wisdom is very unlikely to fail to notice side effects of socioeconomic hubris such as marginalization of the economically vulnerable and the crazy careening of civilization into a climate catastrophe. But there are not many such virtuous souls. So where else does this confrontation actually happen? I think that this confrontation happens mostly in our heads, which is to say, in the heads of philosophers who think deeply about the way human beings understand themselves. But that's not enough, particularly given how urgent the problems are. Once again, it really doesn't matter how clever and potentially revolutionary our anthropological ideas are if they remain 
socially and politically inert. So now we need to discuss the move from conceptual reconstruction in philosophical anthropology to a theory of change.

I want to suggest five directions of change, as follows:

- education about complex social systems, relationality, and species-wide cognitive error,

- activating religious and humanist communities as sites of virtue cultivation,

- strategic policy deployments to counter socioeconomic hubris and its effects,

- advertising campaigns to explain the importance of love and wisdom, and

- explicit political rhetoric about the problems of individualism and cognitive error.

To pull any of this off, partnerships are critical. Philosophers need to team up with educators and policy professionals because philosophers will not achieve practical results of this kind by themselves. I think the main impediment to such partnerships lies in the ability of philosophers to convince practically oriented change agents and on-the-ground stakeholders that philosophical anthropology has anything of importance to offer. So let's start there.

How do philosophers make the case to practically minded change agents such as educators and policy experts that visions of the human person powered by the virtues of love and wisdom can effectively confront the problems associated with invidious individualism and chronic cognitive error? It sounds like a pipe dream, or perhaps some kind of religious vision. Wouldn't it be better to focus on economic prosperity, calming people's anxieties, and projecting strength on the world stage? Isn't expecting people to become enlightened enough to qualify as loving and wise asking way too much? Anyway, why would anyone trust a philosopher who claims that the virtues of love and wisdom can make all the difference in a life-and-death confrontation with the problems that beset us?

There are ways for philosophers to navigate around their well-earned reputation for being irrelevant to socioeconomic challenges. But they will make most philosophers nervous. The trick is to engage policy experts and educators by showing them the difference that love as agape and karuna and wisdom as knowledge and humility can make. Because nobody will trust a philosopher to experiment in the real world, that difference will have to be demonstrated in some other way, and I want to suggest four such methods.

First, philosophers can demonstrate the difference their ideas can make using inspiring word pictures capable of captivating the imagination of journalists and educated readers. This is one method by which powerful ideas spread. Of course, the directions and extend of spread critically depends on the nature of communication and the stakeholders involved. So consider a few examples.

The Berggruen Prize for Philosophy and Culture is an annual "award for major achievements in advancing ideas that shape the world" (https://www.berggruen.org/ prize/). Three philosophers have won that prize, each invested in partnerships that spread powerful ideas and create conditions conducive to socioeconomic change, but the way those partnerships work has been quite different. Canadian philosopher Charles Taylor has primarily influenced other university intellectuals but he is also a public intellectual with a strong media presence striving to support conditions he 
thinks will unify societies in the face of increasing cultural diversity. British philosopher and public servant Baroness Onora Sylvia O'Neill has brought her philosophical-ethics perspective to policy and politics in the UK House of Lords, raising consciousness and creating positive change on everything from bioethics to civic life. American philosopher Martha Craven Nussbaum has combined the highest scholarly standards with a role as a public intellectual, partnering with economist Amartya Kumar Sen to create an intellectual framework for welfare economics (the capability approach) that has had a profound effect in numerous policy directions, including the design of the United Nations' Human Development Index. In all three cases, these philosophers maintain a complex web of partnerships that give practical leverage to their profound ideas about the human condition.

Similarly, the Templeton Prize recognizes people from a wide variety of disciplines who have "made an exceptional contribution to affirming life's spiritual dimension, whether through insight, discovery, or practical works" (http://www. templetonprize.org/purpose.html). Sometimes a philosopher is a recipient of the Templeton Prize (e.g. Alvin Plantinga, Jean Vanier, Tomáš Halík, Michael Heller, Charles Taylor, Michael Novak) and in each of those cases there is a key dimension of public influence that involves partnerships beyond philosophy to leverage creative philosophical ideas for meaningful social change. Sometimes the partnership takes the form of a media presence, spreading potent ideas in persuasive ways; sometimes the partnerships are with change agents and other kinds of intellectuals to spread ideas and social change strategically.

Many media venues focus on the power of ideas to change self-understanding and behavior, and ultimately to transform socioeconomic values and practices. Articulate philosophers sometimes participate in such processes of public education and transformative enlightenment. Consider just one example: the National Public Radio (NPR) program “On Being,” hosted by Krista Tippett (https://onbeing.org/). This Peabody Award-winning radio show and podcast asks: "What does it mean to be human? How do we want to live? And who will we be to each other?" and has an inspiring mission: "Pursuing deep thinking, social courage, moral imagination, and joy, to renew inner life, outer life, and life together." Airing on more than 400 public radio stations across the United States, On Being's podcasts have been downloaded or played online more than 200 million times. And who is listening? NPR as a whole classifies its audience into six groups - the business leader, the cultural connoisseur, the educated lifelong learner, the civic leader, the sustainability champion, and the curious explorer - and makes the following claims about its audience:

Across platforms, NPR reaches the nation's best and brightest. On air and online, the NPR audience is influential and curious. They are learning more and leading more. Connected to their local communities and tuned in to the latest public affairs and cultural conversations, the NPR audience embodies the thought and opinion leader. (https://www.nationalpublicmedia.com/npr/audience/)

Presumably it would be a subset of that group who engages with On Being. The kind of flow of ideas represented here is therefore top down, penetrating not far beyond the realm of opinion leaders and educated elites. These are the people most influential on policy, to be sure, but it is very different from the kind of bottom-up 
idea-flow seen in recent American political campaigns, such as those of Barak Obama, Donald Trump, and Bernie Sanders. There is nothing wrong with top-down communication focused on cultural elites and this is probably the best philosophers can hope for but it is also important to recognize the limitations of that kind of idea flow, if only to avoid over-idealization and self-deception about influence of bright and shiny philosophical conceptions of the human being.

Second, philosophers can demonstrate the difference their ideas make by partnering with educators to design new kinds of curricula for schools and informal education settings for both children and adults. I am not thinking here of philosophy of education, which is an important part of the academic fields of both philosophy and education, and a notable focus of philosophical literatures in many cultures from Confucius and Plato down to the present. Rather, I have in mind the content of educational practice, regardless of the prevailing normative educational philosophy. Philosophers could partner with educators on many fronts, helping to raise consciousness and to make the case for reforming educational practices.

Consider the sobering fact that there is not a single educational program in existence that systematically teaches students (either children or adults) about their tendencies to cognitive error and equips them with the skills needed to contest those tendencies. We have known about most of the tendencies on the Codex of Tendencies to Cognitive Error for the better part of a century at this point and we have had solid empirical evidence on all of them for several decades yet cognitive psychology and philosophy (especially epistemology) have not been able to create the kinds of partnerships with educators that would put in place the educational processes that are so clearly needed. Doing so would be the single most important contribution we could make to improving the civility of public discourse and resisting the biases that are both the enemy of sound policy debate and the ally of populist xenophobic nationalism. Of course, individual lines of training achieve something in this direction, as when historians are trained out of tendencies to anachronism, scientists are taught not to mistake correlation for causation, mathematicians become expert in interpreting statistics, and humanities training helps people acquire skills for critical reasoning and hermeneutical sophistication. But this merely describes a piecemeal approach to an educational challenge that should be confronted comprehensively, with philosophers helping to drive the process of educational reform.

Third, philosophers can demonstrate the difference their ideas make by partnering with change agents such as non-profits and politicians to change public rhetoric about socioeconomic systems. Martha Nussbaum's collaboration with Amartya Sen is a fine example, producing a better way of thinking about social welfare and a more accurate way of measuring human development. The work of the Center for Mind and Culture includes partnerships between philosophers and scientists aimed at increasing public understanding of complex dynamical systems and thereby spreading awareness of the challenges associated with so-called "wicked problems" that resist neat solutions and frequently involve unintended side effects.

Much more of this could be done. The critical factor in how much actually occurs, I suspect, is the intention of philosophers. Change agents operate at some distance from the intricate qualifications and careful conceptual analyses of 
university philosophers. They look for the neat turn of phrase that captures attention, whereas the typical philosopher finds such simplifications irksome at best and tendentious at worst. Philosophers could wash their hands of such practices but, in so doing, they impoverish the work of such change agents. Some philosophers those who want their work to influence public discourse, public policy, and the thinking of regular people - need to get engaged and make their philosophical skills count for formulating less misleading slogans and better material to back up those slogans, increasing depth and breadth of intellectual vision without sacrificing focus and reach of the message of change.

Fourth, and here we come to something quite radical, philosophers can use virtual societies to demonstrate the difference philosophical ideas can make. Seriously?! Yes: computer simulation is a valuable path to rehabilitating the public image of contemporary philosophical anthropology as socially useless. When a policy expert challenges philosophers who are swept away by their own rhetoric to make good on their seemingly outrageous claims about how to improve socioeconomic systems, computational modeling and simulation may be the only feasible option.

I'm referring to something like computer games, but where the aim is accuracy rather than entertainment. If philosophical recommendations are actually sound and worth the attention philosophers think they deserve, then it ought to be possible to rise to the policy expert's challenge by building a multi-agent artificial intelligence computational model of artificial societies with and without the envisaged change in human self-understandings. Calibrate the model against the world the way it is now and then see what happens when you increase the frequency of people who understand relationality and cultivate the virtue of love, and people who are self-aware about cognitive error and cultivate the virtue of wisdom. Does the world get better in the expected way or not? And what are the precise pathways of change? Then turn the challenge around and demand that the policy experts implement their own proposals for the way the world is supposed to improve and see which vision of the human future fares better.

Computational simulations are ideal for studying complex adaptive social systems, which is why the field of social simulation has been growing for several decades. After all, it's a matter of using a virtual complex system to model a realworld complex system. The subfield of human simulation is particularly relevant because that's where computer engineers engage the arts and humanities disciplines such as philosophy (see Diallo et al. 2019). Human simulation is the ideal venue for helping philosophers make good on their claims about the importance of their conceptual reconstructions in philosophical anthropology and earn their way into public policy and education debates. If Plato and Confucius had computer simulations to work with, they could have implemented their vision of human life in an artificial society and decided that they were being too idealistic, or that they should tweak their ideas a bit, or that they should drive on toward implementation as quickly as possible.

But is this really feasible? Here's what John Teehan, a philosopher at Hofstra University in New York, said after working with one of our computational modeling and simulation teams at the Center for Mind and Culture (CMAC): 
After two (intense) days with the people at CMAC, going through the process of translating my hypothesis about religion and empathy into the language of computer modeling, it all began to make sense ... Because of this method, we will actually be able to bring some data into a debate that would otherwise remain largely in speculation ... It forced me to formulate my ideas in such precise and concrete terms (so they could be coded for) that I came away with a better understanding of my own theory. (mindandculture.org)

Making use of human simulation is one way for philosophers to win the attention of educators and policy professionals. Once a partnership is forged, anything can happen. All five directions of change I listed earlier are well and truly on the table for discussion and action, along with other possibilities that policy experts and educators will be a lot better at dreaming up than an idealistic philosopher. After that, the game really is afoot!

\subsection{Conclusion}

The five directions of change and the four types of partnerships I have discussed are fertile soil for growing collaborative ventures with genuinely transformative potential, all directed by realistic theories of change. I wish there were many recent and relevant and renowned examples of innovations in philosophical anthropology impacting social policy in western capitalist democracies. I'm aware of only a few but I have pointed to partnerships in which philosophers engage educators and policy professionals on questions rooted in philosophical anthropology, trying to create the right kinds of impacts. Along with the organization I lead, the Center for Mind and Culture, I'm involved in several such partnerships studying a variety of pressing social issues where philosophical visions of the human condition play critical roles: commercial sexual exploitation of children, the integration of non-western immigrants and refugees in western cities, the crisis of rural suicide, the social and economic consequences of climate change, and others. For us, human simulation is a key tool used to translate from the conceptual domain to the practical domain, creating the possibility of winning the attention of educators and policy professionals in those projects. That method got us into the debate by demonstrating that our ideas aren't just speculative talk; we gave the change agents a reason to look twice and engage us directly. Not every philosopher can build computational simulations or create partnerships with educators and policy professionals, but not every philosopher needs to; it's a task for a team. Experts in philosophical anthropology can design models with computer engineers who build them, and that's just the beginning of fruitful partnerships. Philosophers can consult on educational curricula with educators, and on advertising campaigns with politicians and non-profits, while policy professionals add realism and relevance and thinking about strategic change.

Reconfigured philosophical ideas about human nature can't make any difference unless philosophers partner with change agents. Change agents can't change anything in a good way unless it is thought through soundly first, and nobody is better than philosophers at thinking carefully about things. The era of the solo intellectual 
is over for scholars who want to influence a troubled world. We have entered the era of collaborative research. And we as philosophers need to engage, and stay engaged, if we want to be relevant. Working with others, under the aegis of realistic theories of change, philosophers have a lot to say about the problems of individualism and cognitive error plaguing western socioeconomic practices and about the virtuous ideals of love and wisdom that are capable of transforming those practices.

\section{References}

Diallo, S.Y., W.J. Wildman, F. LeRon Shults, and A. Tolk. 2019. Human Simulation: Perspectives, Insights, and Applications. Leiden: Brill.

Mill, J.S. 1836. On the Definition of Political Economy, and on the Method of Investigation Proper to It. London and Westminster Review 4.

Scaringe, S.A., and W.J. Wildman. 2020. Biological Mutualism: A Notable Advance and a Hint of Things to Come. Theology and Science 18 (2): 211-225.

Solomon, S., J. Greenberg, and T. Pyszczynski. 2015. The Worm at the Core: On the Role of Death in Life. New York: Random House.

Wildman, W.J. 2009. Science and Religious Anthropology: A Spiritually Evocative Naturalist Interpretation of Human Life. Aldershot: Ashgate.

- 2010. An Introduction to Relational Ontology. In The Trinity and an Entangled World: Relationality in Physical Science and Theology, ed. J. Polkinghorne and J. Zizioulas, 55-73. Grand Rapids: Eerdmans.

- 2019. Love and Desire, Human and Divine: A Trans-religious Naturalist Account. In Theology Without Walls, ed. J. Martin, 138-150. New York: Routledge.

Open Access This chapter is licensed under the terms of the Creative Commons Attribution 4.0 International License (http://creativecommons.org/licenses/by/4.0/), which permits use, sharing, adaptation, distribution and reproduction in any medium or format, as long as you give appropriate credit to the original author(s) and the source, provide a link to the Creative Commons license and indicate if changes were made.

The images or other third party material in this chapter are included in the chapter's Creative Commons license, unless indicated otherwise in a credit line to the material. If material is not included in the chapter's Creative Commons license and your intended use is not permitted by statutory regulation or exceeds the permitted use, you will need to obtain permission directly from the copyright holder. 